\title{
Taksonomi Lalat di Pasar Induk Jakabaring Kota Palembang
}

\author{
Yunita Panca Putri \\ e-mail: yunita_pp12@yahoo.co.id \\ Program Studi Biologi Fakultas MIPA Universitas PGRI Palembang
}

\begin{abstract}
Research on Flies Taxonomy at the Jakabaring Main Market of Palembang City has been carried out. The study was conducted in January-May 2015 located at the Jakabaring Central Market, Palembang City. This study aims to examine the types of flies in the Jakabaring Central Market of Palembang City. The types of flies found were identified and classified in the Entomology Laboratory, Department of Pests and Plant Diseases, Faculty of Agriculture, UNSRI Indralaya. . Hasil penelitian menunjukkan jenis-jenis lalat yang ditemukan dapat di Pasar Induk Jakabaring Kota Palembang terdiri dari 5 spesies yang tergolong ke dalam 1 ordo, 3 familia, 5 genus.
\end{abstract}

Key words : Taxoonomy, flies, Jakabaring main market of palembang city.

\begin{abstract}
ABSTRAK
Telah dilakukan penelitian Taksonomi Lalat di Pasar Induk Jakabaring Kota Palembang. Penelitian dilaksanakan bulan Januari-Mei 2015 berlokasi di Pasar Induk Jakabaring Kota Palembang. Penelitian ini bertujuan mengkaji jenis-jenis lalat di Pasar Induk Jakabaring Kota Palembang. Jenis lalat yang ditemukan diidentifikasi dan diklasifikasikan di Laboratorium Entomologi Jurusan Hama dan Penyakit Tumbuhan Fakultas Pertanian UNSRI Indralaya. Hasil penelitian menunjukkan jenis-jenis lalat yang ditemukan dapat di Pasar Induk Jakabaring Kota Palembang terdiri dari 5 spesies yang tergolong ke dalam 1 ordo, 3 familia, 5 genus.
\end{abstract}

Kata kunci : Taksonomi, lalat, pasar induk Jakabaring Palembang

\section{PENDAHULUAN}

Lalat termasuk ordo Diptera, merupakan salah satu ordo terbesar dari serangga dengan keragaman jenis yang tinggi dan sebagian besar tersebar secara kosmopolitan. Kebanyakan Diptera bertubuh lunak serta mempunyai kepentingan ekonomi yang cukup besar (Borror et al., 1992).

Lalat untuk mempertahankan kehidupannya dan daya tariknya terhadap bau-bau yang busuk menuntun lalat untuk mencari tempat-tempat yang kotor untuk mencari sesuatu yang dapat dimakannya. Biasanya tempat-tempat tersebut adalah tempat yang banyak berhubungan dengan aktivitas manusia, diantaranya adalah Pasar.

Pasar Jakabaring merupakan pasar induk di kota Palembang, karena menyuplai sayur, buah maupun ikan/daging dalam jumlah banyak dari berbagai daerah di kota Palembang, sehingga para pedagang dapat membeli dalam jumlah banyak kebutuhan dengan harga yang lebih murah, untuk kemudian dijual kembali. Pasar induk Jakabaring terletak di kawasan Jakabaring, Kelurahan 15 Ulu dan Kelurahan 8 Ulu. Aktifitas pasar 
Jakabaring mulai berlangsung pada pukul 22.00 WIB. Pukul 09.00 WIB, aktifitas pasar sudah sepi karena dagangan sudah habis, yang tersisa hanyalah sampahsampah.

Pasar merupakan tempat manusia melakukan aktivitas jual beli untuk mendapatkan berbagai jenis bahan makanan, seperti ikan, daging, sayur dan buah sehingga dari aktivitas tersebut akan menghasilkan sampah dan menjadikan lingkungan pasar menjadi kotor dan bau. Belum lagi tumpukan-tumpukan sampah dalam volume yang lebih kecil di beberapa sudut lorong pasar. Saluran air dari limbah pasar kerap tersumbat dengan air berwarna kehitaman dan berbau. Kondisi lingkungan tersebut dapat mendukung lalat untuk mendapatkan makanan dan berkembangbiak. Pasar Jakabaring adalah penyumbang sampah dengan volume terbesar yaitu sekitar $15,53 \mathrm{~m}^{3} /$ hari disusul oleh pasar Plaju dan pasar Soak Batu masing-masing sebesar $9.08 \mathrm{~m}^{3} /$ hari dan $6,07 \mathrm{~m}^{3} /$ hari. Hampir $50 \%$ dari total sampah yang dihasilkan dari kegiatan pasar di kota Palembang tergolong sebagai sampah organik (Bahrin et al., 2011). Hasil penelitian Putri et al., (2013), pada lokasi penjualan ikan segar di Kota Padang ditemukan 5 species lalat yaitu Musca domestica, C. megacephala, Lucillia sp., Calliphora sp., Sarcophaga sp.

Selama ini informasi mengenai jenis-jenis lalat yang terdapat di Pasar Induk Jakabaring Palembang belum banyak diketahui. Maka dari itu perlu dilakukan penelitian mengenai jenis-jenis lalat yang terdapat di Pasar Induk Jakabaring Palembang, yang selanjutnya dapat digunakan sebagai referensi untuk pengendalian lalat di Pasar Induk Jakabaring Kota Palembang.

\section{BAHAN DAN METODE}

\section{Waktu dan Tempat}

Penelitian dilaksanakan pada bulan Januari sampai bulan Mei 2015. Tempat pengambilan sampel Lalat adalah Pasar Induk Jakabaring Kota Palembang. Tempat penelitian adalah Laboratorium Entomologi Jurusan Hama dan Penyakit Tumbuhan Fakultas Pertanian UNSRI Indralaya.

\section{Alat dan Bahan}

Alat-alat yang digunakan pada penelitian ini meliputi jaring penangkap lalat (insect net), kertas umpan berperekat, botol koleksi, pinset, kamera. Sedangkan bahan yang dibutuhkan adalah Lalat dan alkohol $70 \%$.

\section{Cara Kerja}

\section{- $\quad$ Penangkapan lalat}

Penangkapan lalat dengan menggunakan kertas umpan berperekat yang diletakkan pada setiap titik pengambilan sampel di masing-masing lokasi penelitian dari pukul 08.00 WIB sampai pukul 10.00 WIB.

Penangkapan lalat diambil di plot penjualan sayur, plot ikan, plot daging, plot buah dan plot sembako sebanyak $3 \mathrm{x}$ penangkapan. Dilakukan 1 minggu sekali, selama 3 minggu. Populasi lalat adalah seluruh lalat yang berada di lokasi penelitian Lalat yang tertangkap dimasukkan ke dalam botol koleksi dan diberi label sesuai dengan tanggal dan lokasi pengambilan sampel. Semua lalat yang ada dibunuh dengan cara menempatkannya di dalam frezer selama 30 menit.

\section{- Identifikasi Lalat}

Lalat-lalat yang diperoleh selama pengamatan diidentifikasi berdasarkan morfologinya, seperti ukuran tubuh,warna tubuh, karakteristik kepala, alat mulut, antenna, tungkai/kaki, dan sayap.

Untuk keperluan identifikasi lalat, digunakan kunci identifikasi menggunakan buku Borror et al., (1992) dan Kalshoven (1981). Identifikasi lalat dikerjakan secara makroskopis dan 
mikroskopis (dengan Stereomikroskop) dan didasarkan pada semua gambaran dalam struktur anatomis luar tubuh lalat.

\section{HASIL DAN PEMBAHASAN}

Hasil identifikasi jenis-jenis lalat yang ditemukan dapat di Pasar Induk Jakabaring Kota Palembang terdiri dari 5 spesies yang tergolong ke dalam 1 ordo, 3 familia, 5 genus (Tabel 1).

Tabel 1. Spesies lalat (Diptera) yang ditemukan di Pasar Induk Jakabaring Palembang (3x penangkapan).

\begin{tabular}{|c|c|c|c|c|c|}
\hline No. & Ordo & Familia & Genus & Spesies & Nama Lokal \\
\hline 1. & Diptera & Muscidae & Musca & Musca domestica. & Lalat rumah \\
\hline 2. & & & Fannia & Fannia sp. & Lalat kecil \\
\hline 3. & & Calliphoridae & Chrysomya & $\begin{array}{l}\text { Chrysomya } \\
\text { megacephala }\end{array}$ & $\begin{array}{l}\text { Lalat hijau kebiruan } \\
\text { metalik }\end{array}$ \\
\hline 4. & & & Lucilia & Lucilia sp. & Lalat hijau metalik \\
\hline 5. & & Sarcophagidae & Sarcophaga & Sarcophaga sp. & Lalat abu-abu \\
\hline
\end{tabular}

Sumber : Data penelitian

\section{Ciri-ciri Morfologi Lalat yang ditemukan}

1. Lalat rumah (Musca domestica).

Lalat rumah (M. domestica) tergolong ke dalam Famili Muscidae (Borror et al., 1992). Hasil pengamatan dan pengukuran ciri-ciri morfologi M. domestica menunjukkan Kepala besar berwarna

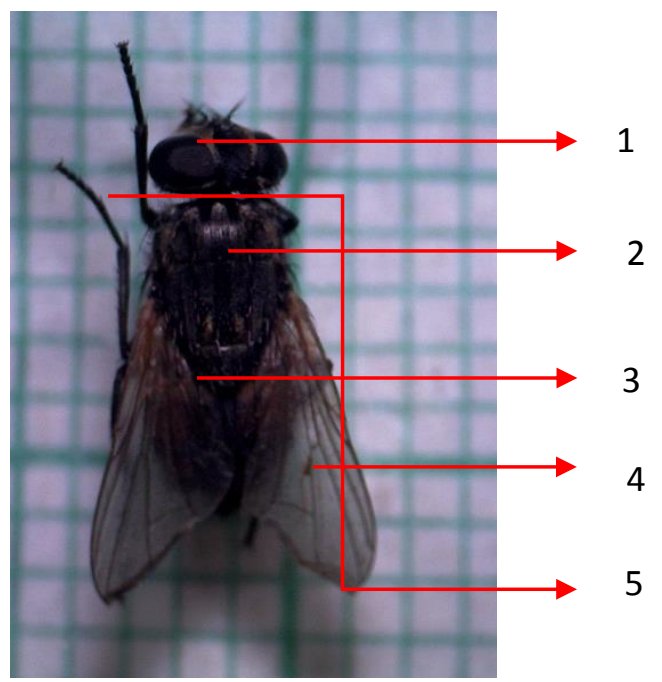

(a)

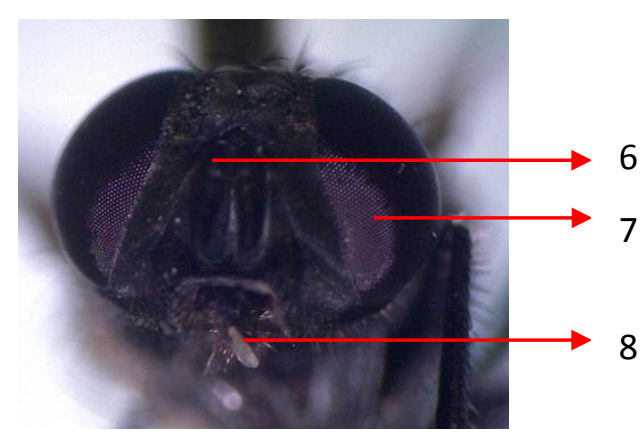

(b)

Gambar 1. Lalat Musca domestica

Keterangan :

(a). Imago secara keseluruhan

1. caput (kepala) 2. Thorax (dada) 3. Abdomen (perut) 4. Sayap 5. Tungkai

(b). Kepala tampak dari depan

6. antena 7. Mata majemuk 8. Mulut 


\section{Lalat kecil (Fannia sp.).}

Hasil pengamatan dan pengukuran ciriciri morfologi Fannia sp. menunjukkan bahwa mata berwarna coklat gelap. Panjang tubuh berkisar antara 6,5 - $7 \mathrm{~mm}$ dan venasi sayap berkisar antara 3,8 - 4,5

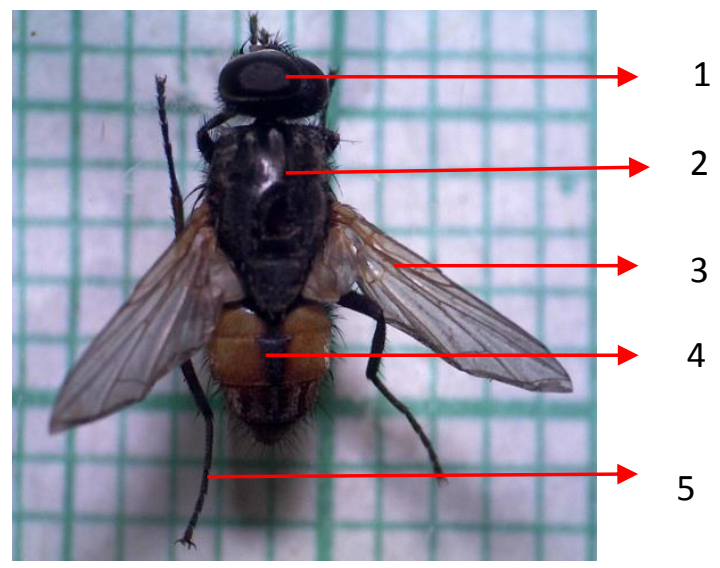

(a) mm. Menurut Borror et al., (1992), Fannia sp. kelihatan seperti lalat rumah tetapi ukuran jauh lebih kecil, berkembangbiak di kotoran manusia dan hewan dan juga dibagian-bagian tumbuhan yang membusuk, misalnya di tumpukan rumput yang membusuk.

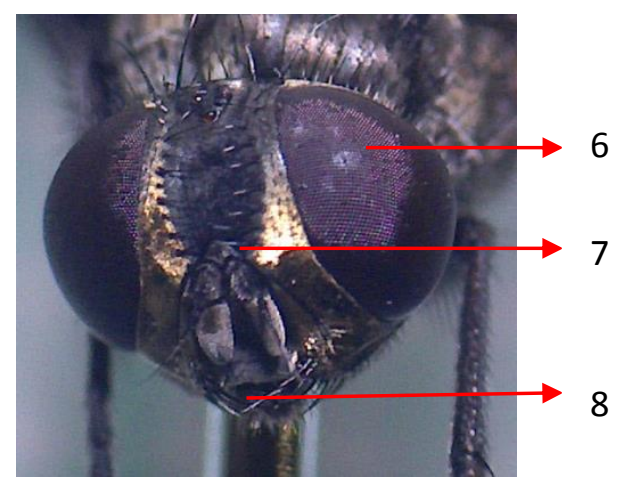

(b)

Gambar 2. Lalat Fannia sp.

Keterangan :

(a). Imago secara keseluruhan

1. caput (kepala) 2. Thorax (dada) 3. Tungkai 4. Sayap 5. Abdomen (perut).

(b). Kepala tampak dari depan

6. antena 7. Mata majemuk 8. Mulut

3. Lalat hijau kebiruan metalik (Chrysomya megacephala).

Hasil pengamatan dan pengukuran ciriciri morfologi C. megacephala menunjukkan bahwa mata berukuran besar dan berwarna merah gelap, pada bagian mulutnya berwarna kuning. Warna tubuh hijau kebiruan metalik, panjang tubuh berkisar antara 7,3 - 9,5 mm, panjang venasi sayap berkisar antara 4,6 -
$5 \mathrm{~mm}$, thorax berwarna hijau metalik kecokelatan, permukaan tubuh tertutup dengan bulu-bulu pendek keras dan jarang letaknya. Abdomen berwarna hijau metalik mempunyai garis-garis transversal. Sayap jernih dengan guratan urat-urat yang jelas. $C$. megacephala tergolong ke dalam Famili Calliphoridae. Nama lalat tersebut diberi berdasarkan warna tubuhnya (Borror et.,al, 1992). 


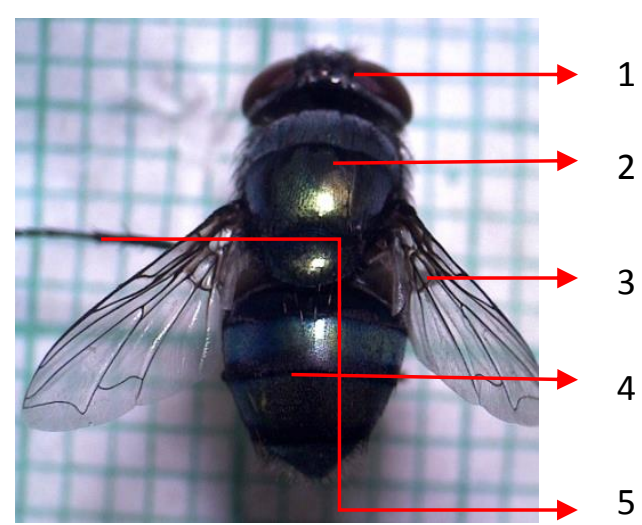

(a)

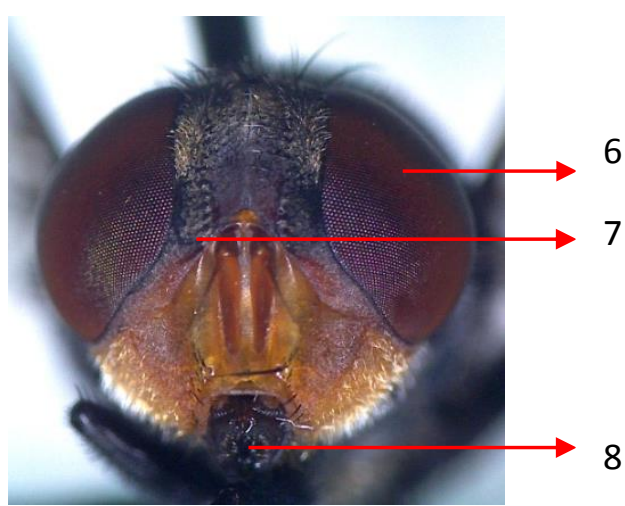

(b)

Gambar 3. Lalat Chrysomya megacephala

Keterangan :

(a). Imago secara keseluruhan

1. caput (kepala) 2. Thorax (dada) 3. Sayap 4. Abdomen (perut) 5. Tungkai

(b). Kepala tampak dari depan

6. mata majemuk 7. Antena 8. Mulut

4.Lalat hijau metalik (Lucilia sp.).

Hasil pengamatan dan pengukuran ciriciri morfologi Lucilia sp. menunjukkan bahwa mata berwarna merah. Panjang tubuh berkisar antara 7,8 - 9,5 mm, warna tubuh hijau metalik, thorax dan abdomen

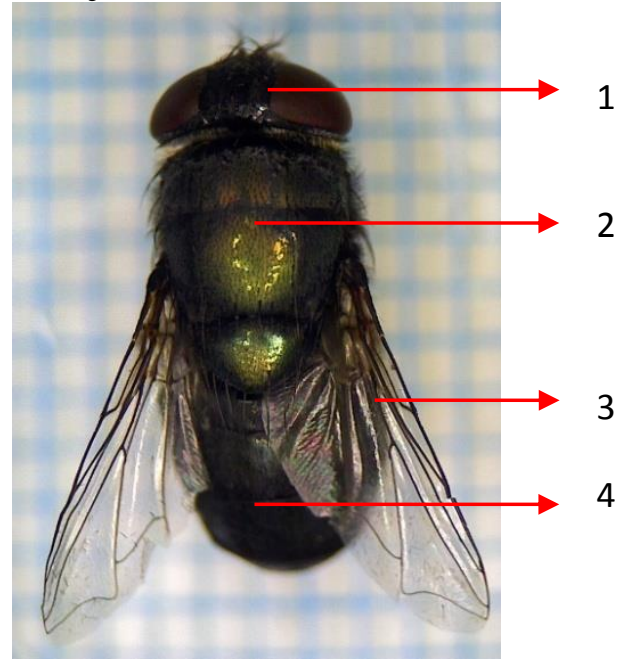

(a) bewarna hijau metalik. Panjang venasi sayap berkisar antara 5,5 - 6,5 $\mathrm{mm}$. Menurut ciri-ciri yang diperoleh Laksmita et al., (2013), tubuh berwarna hijau metalik, mata berwarna merah.

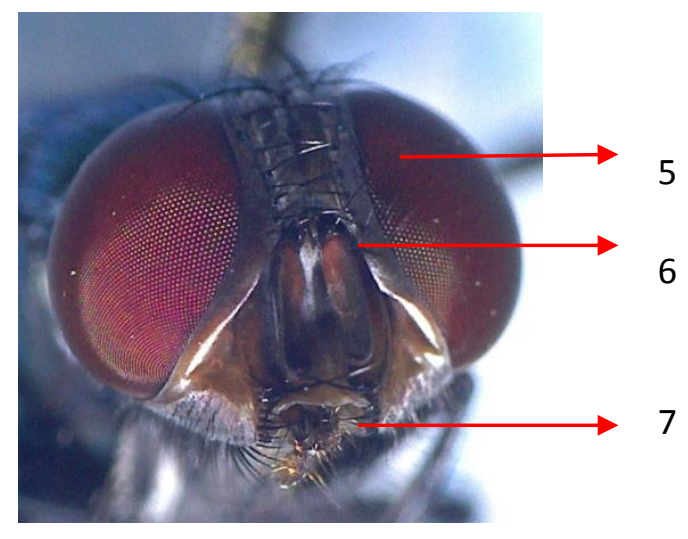

(b)

Gambar 4. Lalat Lucilia sp.

Keterangan :

(a). Imago secara keseluruhan

1. caput (kepala) 2. Thorax (dada) 3. Sayap 4. Abdomen (perut)

(b). Kepala tampak dari depan

5. mata majemuk 6. Antena 7. Mulut 
5. Lalat abu-abu (Sarcophaga sp.)

Hasil pengamatan dan pengukuran ciriciri morfologi Sarcophaga sp. menunjukkan bahwa mata berwarna merah gelap. Panjang tubuh berkisar antara $8-9,5 \mathrm{~mm}$, tubuh berwarna abuabu, dengan bercak-bercak hitam atau

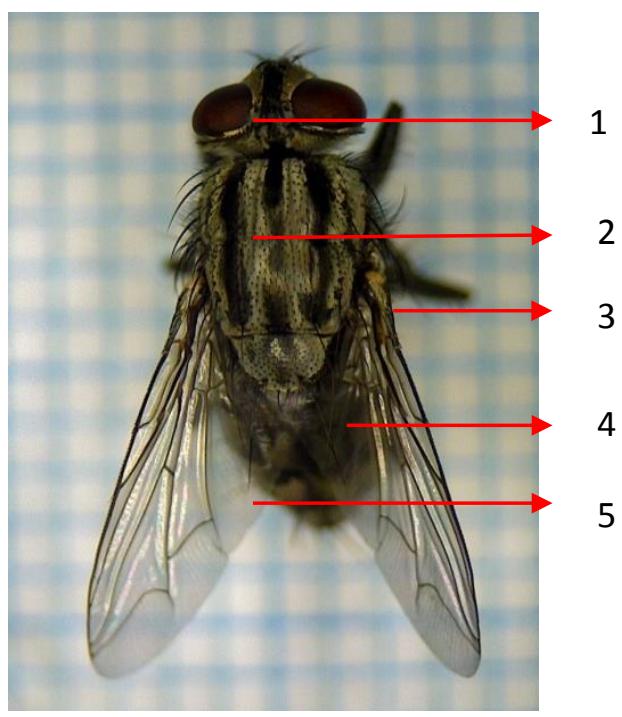

(a) dengan garis-garis hitam memanjang pada thorax, dan abdomen memiliki corak seperti papan catur. Panjang venasi sayap berkisar antara 6,8 - $8 \mathrm{~mm}$. Menurut Lilies (1991), memiliki ciri tubuh berwarna hitam dengan strip pada thorax berwarna abu-abu.

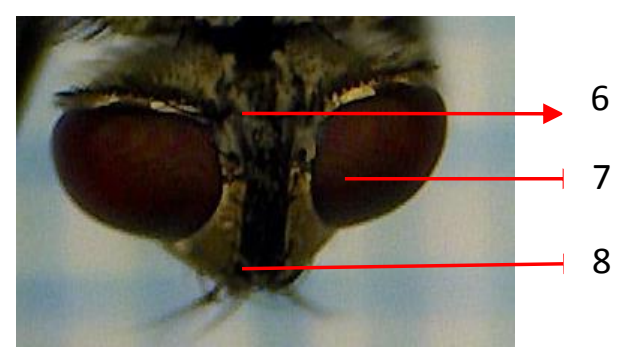

(b)

Gambar 5. Lalat Sarcophaga sp.

Keterangan :

(a). Imago secara keseluruhan

1. caput (kepala) 2. Thorax (dada) 3. Tungkai 4. Sayap 5. Abdomen (perut).

(b). Kepala tampak dari depan

6. antena 7. Mata majemuk 8. Mulut

\section{KESIMPULAN}

Lalat-lalat yang ditemukan di Pasar Induk Jakabaring Kota Palembang terdiri dari 5 spesies yang tergolong ke dalam 1 ordo, 3 familia, 5 genus.

\section{DAFTAR PUSTAKA}

Bahrin D, Anggraini D, dan Pertiwi MB. (2011). Pengaruh Jenis Sampah, Komposisi Masukan Dan Waktu Tinggal Terhadap Komposisi Biogas Dari Sampah Organik Pasar Di Kota Palembang. Fakultas Teknik Universitas Sriwijaya Prosiding Seminar Nasional AVoER ke-3; Palembang, 26-27 Oktober 2011.

Borror, D.J., C.A. Triplehom., and N.F. Jonhson. (1992). An Introduction To The Insect (Partosoedjono, $\mathrm{S}$ dan Mukayat, D.B.) Gajah Mada Universitas Press. Yogyakarta: xviii+1009 hlm.

Hastutiek P dan Fitri LE. (2007.) Potensi Musca Domestica Linn. Sebagai Vektor Beberapa Penyakit. Jurnal Kedokteran Brawijaya, 23(3), 125136. 
Kalshoven LGE. (1981). Pest of Crops in Indonesia. (van der Laan) PT. Ichtiar Baru-van Hoeven. Jakarta.

Laksmita AS, Watiniasih NL, Junitha IK. (2013). Prediksi Lama Kematian Berdasarkan Keberadaan Serangga Genus Lucilia (Calliphoridae) Pada Bangkai Mencit (Mus musculus) di Lokasi Hutan Mangrove. Jurnal Biologi, 17(1), 1-5.

Lilies C. (1991). Kunci Determinasi Serangga. Kanisius. Jakarta: xii +223

Putri, Y.P., Jasmi, Armein, dan Zeswita L. (2013). Keanekaragaman Lalat (Cyclorrapha: Diptera) Pada Lokasi Penjualan Ikan Segar Di Kota Padang. Universitas Andalas Padang. Jurnal of Biological Education, 2(2), 1-6 